\title{
Acknowledgment to Reviewers of Eng in 2021
}

\section{Eng Editorial Office}

Citation: Eng Editorial Office.

Acknowledgment to Reviewers of Eng in 2021. Eng 2022, 3, 99. https:// doi.org/10.3390/eng3010008

Published: 28 January 2022

Publisher's Note: MDPI stays neutral with regard to jurisdictional claims in published maps and institutional affiliations.

Copyright: $\odot 2022$ by the author. Licensee MDPI, Basel, Switzerland. This article is an open access article distributed under the terms and conditions of the Creative Commons Attribution (CC BY) license (https://creativecommons.org/licenses/by/4.0/).
MDPI AG, St. Alban-Anlage 66, 4052 Basel, Switzerland

Rigorous peer-reviews are the basis of high-quality academic publishing. Thanks to the great efforts of our reviewers, Eng was able to maintain its standards for the high quality of its published papers. Thanks to the contribution of our reviewers, in 2021, the median time to first decision was 24 days and the median time to publication was 45 days. The editors would like to extend their gratitude and recognition to the following reviewers for their precious time and dedication, regardless of whether the papers they reviewed were finally published:

Alberto M. Pernía
Aleksander Tedstone
Alessio Bucciarelli
Alice Berardo
Andrey V. Filippov
Aris Giannakas
Catherine Kelly
Chandarasekaran Ramamurthy
Cristian-Dragoş Dumitru
Davide Rocco
Eugeniusz Koda
Eva Díaz
Gabriela Lisa
Hassan Elahi
Jana Sedlaŕíková
Jen-Yuan (James) Chang
John Radcliffe
José Fortes Lopes
Josef Guttman
Kelin Hu
Kristina Ložienė
Luc Pastur
Marco Monti
Mark James Jackson
Mihaela Morega
Miroslav Pospíšil

Mohammad Nooraiepour

Muhammad Ajaz Ahmed

Nikolai Tsvetkov

Olga A. Azarova

Orlando M. N. D. Teodoro

Pavlos S. Georgilakis

Petar Varbanov

Quynh Thi Tu Tran

Rafael J. Bergillos

Renata Włodarczyk

Rosa Veropalumbo

Shingo Yokota

Siyuan Ji

Stefania Garzoli

Subramanian Sundarrajan

Tomeu Rigo

Travis W. Knight

Viktors Haritonovs

Virgil Florescu

Vladimir Răsvan

Vladimir Vasilyev

Wahid Ferdous

Wojciech Smułek

Wongi S. Na

Zbyněk Sokol 